\title{
Fasting Specimen
}

National Cancer Institute

\section{Source}

National Cancer Institute. Fasting Specimen. NCI Thesaurus. Code C70701.

A specimen obtained from a subject who has abstained from food and possibly water, according to the prescribed amount of time. 